\title{
Manisa İl Merkezinde Bulunan Devlet İlkokul ve Ortaokullarının Fiziki ve Çevresel Koşullarının Değerlendirilmesi
}

\section{Evaluation of Physical and Environmental Conditions of State Primary and Secondary Schools in Manisa City Center}

\author{
Aynur Çetinkaya $^{1}$, Fatma Uyar ${ }^{1 *}$, Dilek Özmen ${ }^{1}$, Damla Şahin Büyük ${ }^{1}$, Sinem Sezen Köksal ${ }^{2}$ \\ ${ }^{1}$ Manisa Celal Bayar Üniversitesi Sağlık Bilimleri Fakültesi Hemşirelik Bölümü, Halk Sağlığı Hemşireliği Anabilim \\ Dalı, Manisa, Türkiye \\ ${ }^{2}$ Çiğli Bölge Eğitim Hastanesi Nöroloji Polikliniği, İzmir, Türkiye
}

\begin{abstract}
e-mail: aynur.cetinkaya@cbu.edu.tr,fatmauyarege@gmail.com,ozmendilek@yahoo.com, damla.sahin44@hotmail.com, sinemkoksalsezen@gmail.com

ORCID: 0000-0003-1599-0070

ORCID: 0000-0002-6826-5238

ORCID: 0000-0002-8288-7623

ORCID: 0000-0002-0623-3951

ORCID: 0000-0001-7569-7170

*Sorumlu yazar/Corresponding author: Fatma Uyar ${ }^{1}$
\end{abstract}

Gönderim tarihi/Received:17.02.2020

Kabul tarihi/Accepted:17.04.2020

DOI:10.34087/cbusbed.690359

\begin{abstract}
Giriş ve Amaç: Araştırmada ilkokul ve ortaokulların fiziki ve çevresel koşullarını değerlendirerek okul çevre sağlığı kapsamında durum tespiti yapmak amaçlandı.

Gereç ve Yöntemler: Araştırma tanımlayıcı kesitsel tipteydi. Araştırmanın evrenini Manisa il merkezinde yer alan 120 okul, örneklemini ise merkez iki ilçeden kura yöntemiyle belirlenen 91 okul oluşturdu. Veriler TSE'nin devlet ilkokul ve ortaokulları için kullandığı değerlendirme formu ve literatür doğrultusunda araştırmacılarca oluşturulan okul fiziksel ve çevresel koşullarını belirlemeye yönelik 62 soruluk anket formu ile toplandı.

Bulgular: Araştırmaya alınan okulların \%31,9'unun 100 metre yakınında tren yolu/ana cadde/ana yol bulunmaktaydı. Okulların \%85,2'sinde dersliklerdeki öğrenci sayısı uygun iken okulların sadece $\% 2,2$ 'sinde öğrenci başına düșen derslik alanı yeterliydi. Okullardaki erkek öğrenci tuvaletlerinin kabin sayısı \%63,6 oranında yeterliyken kız öğrenci tuvaletleri ise \%71,6 oranında yeterliydi. Çalışmadaki okulların sadece \%4,4'ü "Beslenme Dostu Okul”, \%31,9'u "Beyaz Bayrak" sertifikasına sahipti; \%6,6'sında revir, \%3,3'ünde hemşire ve \%1,1'inde hekim bulunmaktaydı.

Sonuç: İncelenen okullardaki çevresel ve fiziki koşulların okul toplumunun sağlığını geliştirme ve korumada yeterli olmadığı bulundu. Cadde/anayol ve tren yolu yakınında bulunan okulların giriş çıkış saatlerinde geçiş güvenliğini sağlayacak bir görevli bulundurulması, Beslenme Dostu Okul, Beyaz Bayrak Projesi gibi projelerin teşvikinin arttırılması, okulların yapılması planlanırken ilgili okul sağlı̆̆ standartlarına uygun ve değişen ihtiyaç ve talepleri karşılayabilecek alt yapıda yapılması, okullarda sağlık personelinin bulundurulmasına yönelik başta hemşireler olmak üzere tüm toplumun bilinçlenmesi sağlanmalıdır.
\end{abstract}

Anahtar Kelimeler: Fiziksel çevre, okul çevre sağlığı, standartlar.

\begin{abstract}
Objective: The aim of the study was to evaluate the physical and environmental conditions of primary and secondary schools and to determine the situation in the scope of school environmental health.

Materials and Methods: The study was descriptive-cross-sectional. The population of the study consisted of 120 schools in the city center of Manisa, and the sample of the sample consisted of 91 schools from two districts. The data were collected with an evaluation form used by TSE for state primary and secondary schools and a 62-question questionnaire to determine the physical and environmental conditions of the school, which was created by the researchers in line with the literature.
\end{abstract}

Results: There was a railway/main street/main road within 100 meters of $31.9 \%$ of the schools surveyed. While $85.2 \%$ of the schools had the number of students in the classrooms, only $2.2 \%$ of the schools had enough classrooms per 
student. While $63.6 \%$ of the male toilets in the schools had enough cabins, $71.6 \%$ of the female toilets were sufficient. Only $4.4 \%$ of the schools in the study had "Nutrition Friendly School" and 31.9\% had "White Flag" certificate; $6.6 \%$ had infirmary, $3.3 \%$ had a nurse and $1.1 \%$ had a physician.

Conclusion: It was found that the environmental and physical conditions in the schools studied were not sufficient to improve and protect the health of the school community. Maintaining a staff member who will ensure the safety of entry and exit of the schools located near the street / main and railway roads, increasing the incentive of the projects such as Nutrition Friendly School, White Flag Project, and making the infrastructure in compliance with the relevant school health standards and meeting the changing needs and demands of the schools. awareness of the whole society, especially nurses, should be ensured for the recruitment of health personnel.

Key words: School environmental health, physical environment, standards.

\section{Giriş}

Okul sağlığı, okul toplumunun sağlığını korumak, sürdürmek ve geliştirmek amacıyla yürütülen çalışmaları kapsar. Okul sağlı̆̆ 1 , okul ve varsa sağlık personelinin işbirliği ile çevre sağlığı, okul sağlı̆̆ hizmetleri ve sağlık eğitimini içeren programların etkin bir şekilde yapılmasıdır [1,2]. 1980'li yıllardan bu yana başta Avrupa'da olmak üzere Dünya Sağlık Örgütü tarafından Sağlığg Geliştiren Okullar (SGO) Ağı Programı uygulanmaktadır. Ülkemizde de 1995 yılından bu yana SGO Ağı kapsamında faaliyetler yürütülmektedir. Bu kapsamda yürütülmesi gereken çalışmalar; sağlığı destekleyen bir okul ortamı ve çevre oluşturma, aileler ve içinde bulunduğu toplumla birlikte çalışma ve öğretim programı içerisinde sağlık eğitimi yoluyla öğrencilerle birlikte çalışma olarak sıralanmıştır [3].

Okul çevre sağlığ 1 , halk sağlığ 1 hizmetlerinin bir parçası olan okul sağlığı çalışmaları için vazgeçilmezdir. Sağlığın geliştirilmesinde eğitimin önemi vurgulanırken okul çevresinin iyileştirilmesinin eğitimin başarısı ve sağlık durumu üzerine etkisinin önemi de vurgulanmaktadır [4-6].

Okul sağlığ1 hizmetleri kapsamında okul sağlığ1 hemşirelerinin okul çevresi ile ilgili görev yetki ve sorumlulukları arasında görev yaptığı okulda okul sağlığı hizmetleri ile ilgili sorunları, gereksinimleri

\section{Gereç ve Yöntem}

\subsection{Araştırmanın Amacı ve Tipi}

$\mathrm{Bu}$ araştırma ile Manisa il merkezinde bulunan devlet ilkokul ve ortaokulların fiziki ve çevresel koşullarını (okul binası, okulun yakın çevresi, oyun alanı, hijyen, beslenme gibi imkanlar yönünden) değerlendirerek okul çevre sağlığı kapsamında durum tespiti yapmak amaçlandı. Araştırma tanımlayıcı kesitsel tipte planland.

2.2 Araştırmanın evreni ve örneklemi

Araştırmanın evrenini Manisa il merkezinde yer alan Milli Eğitim Müdürlüğü'ne bağl1 120 ilkokul ve ortaokul oluşturdu. Araştırmada örnekleme birimi 2.3 Veri Toplama Araçları

Araştırmada bazı koşulların uygunluğu TSE'nin “TS 9518 (2000) İlköğretim Okulları-Fiziki YerleşimGenel Kurallar [12]”, “TS 12014 (1996) Çevre Sağlığ1-Okullar [13]” ve “TS 9111 (2011) Özürlüler ve Hareket Kısıtlılığı Bulunan Kişiler İçin Binalarda Ulaşılabilirlik Gerekleri [14]' standartları kullanılarak devlet ilkokul ve ortaokulları için saptama ve okul idaresine bildirme ve sağlık risklerinin erken tanılanması ve uygun girişimlerin planlanması, gereken önlemlerin alınması konusunda okul idaresiyle koordinasyonu sağlama" yer almaktadır [7].

Sağlıklı okul çevresi hem öğrencilerin hem de personelin fiziksel ve psikolojik sağlıklarını en üst düzeye çıkarmada gereklidir [5]. Nitekim Sürdürülebilir Kalkınma Hedefleri'nden biri olan 'Nitelikli Eğitim', hedeflerinde de kapsayıcı ve emniyetli okullar inşa edilmesi, mevcutlarının iyileştirilmesi amaçlanmıștır [8, 9]. Diğer taraftan çocuk ve güvenlik konusunda güvenli toplumlar programı altında bir program olarak güvenli okul kavramı ortaya atılmıştır. Güvenli okul kavramıyla güvenli bir okul ortamı geliştirerek sürdürmek, okul ve çevresindeki sorunların ortadan kaldırılması/azaltılması, okul, aile ve toplumla birlikte çocuğu koruma stratejileri geliştirmek amaçlanmaktadır. Yapılan çalışmalarda okullarda çevresel risklerin saptanması ve değerlendirilmesi için birimlerin olması gerektiği vurgulanmaktadır $[10,11]$.

$\mathrm{Bu}$ çalışmada ilkokul ve ortaokulların fiziki ve çevresel koşullarını değerlendirerek okul çevre sağlığı kapsamında durum tespiti yapmak amaçlandi.

okul olarak belirlendi. Araştırma örneklemini Epiinfo 2000 programında örneklem birimi okul sayısı alınarak $\% 50$ bilinmeyen prevalans, $\% 95$ güven aralığı, 0,05 sapma miktarı ile en küçük örneklem sayıs1 91 okul olacak şekilde belirlendi. Manisa'da bulunan merkez iki ilçeye (Yunusemre ve Şehzadeler) tabakalı örnekleme yapıldığında 41 okul Şehzadeler ilçesinde, 50 okul Yunusemre ilçesinde kura yöntemiyle belirlendi.

\subsubsection{Araştırmaya dahil olma kriterleri}

Manisa il merkezinde yer alan ilkokul ve ortaokul olmak ve devlet okulu olmak araştırmaya dahil edilme kriterleri olarak belirlendi. Araştırmaya özel okullar dahil edilmedi.

kullandığ1 değerlendirme formu ve literatür doğrultusunda $[1,2,4,5]$ araştırmacılarca oluşturulan okul fiziksel ve çevresel koşullarını belirlemeye yönelik veri toplama formu ile (toplam 62 soru içeren) topland.

\subsubsection{Veri Toplama Süreci}

Veriler okul yönetimi ile iletişime geçilerek okul yönetiminin uygun gördüğü zamanlar içinde 
toplandı. Veriler iki aşamada toplandı. Birinci aşamada kurum yetkilileri (okul müdürü katılımı \%35,2; müdür yardımcısı katılımı \%64,8) okula ilişkin soruları yanıtladı. İkinci aşamada ise okulun lavaboları, yangın merdiveni, ilk yardım dolabı, koridor genişliği, sınıfların genişliği ve aydınlatma durumları, okul bahçesi ve öğrencilerin oyun alanı, kantin temizliği ve kantinde satılan yiyeceklerle ilgili veriler birebir gözlem ve ölçüm yapılması şeklinde topland. Veri toplama formunun doldurulması yaklaşık 45 dakika sürdü.

\subsection{Araştırmanın Etik Yönü}

Araştırma protokolü Manisa Celal Bayar Üniversitesi Tıp Fakültesi Sağlık Bilimleri Etik Kurulu tarafından onaylandı (tarih: 10.06.2015; protokol no: 20478486/248). Manisa İl Milli Eğitim Müdürlüğü'nden kurum izni alındı. Veri toplama süreci etik kurul onayı ve kurum izinleri sonrası gerçekleştirildi. Araştırmada okul yönetiminde çalışan katılımcılara çalışmaya gönüllü olarak katıldıklarını ifade eden gönüllü onam formu imzalat1ld1.

\subsection{Istatistiksel Analiz}

Araştırma verileri, bilgisayar ortamında SPSS 15 paket programında kodlanarak sayı-yüzde dağılımları yapıldı. Durum saptaması için okul bazında veriler tanımlayıcı istatistiklerle değerlendirildi. Verilerin değerlendirilmesinde; değişkenlerin türüne göre hesaplanan tanımlayıcı istatistiklerden (ortalama, standart sapma, minimum ve maksimum, yüzdelik dağılımlar) yararlanıldı.

\section{Bulgular}

Araştırmaya dahil edilen okulların \%51,6'sı ilkokul, $\% 53,8$ ' i ikili öğretimdi. Çalışmadaki okulların \%4,4' ü ''Beslenme Dostu Okul', \%31,9'u '’Beyaz Bayrak' sertifikasına sahipti; \%6,6'sında revir, $\% 3,3$ 'ünde hemşire ve $\% 1,1$ 'inde hekim bulunmaktayd1.

Okulların tamamında şebeke suyu kullanmaktaydı. Okulların \%85,2'sinde dersliklerdeki öğrenci sayıs1 uygun iken okulların sadece \%2,2'sinde öğrenci başına düşen derslik alanı yeterliydi. Okulların $\% 6,6$ 'sında bodrum katında derslik vardı ve sadece \%5,5'inde öğrenci başına düşen beden eğitimi salonu alanı yeterliydi (Tablo 1).

Tablo 1. Okul Binasının Fiziksel ve Çevresel Koşullarının Dağılımı (n=91)

\begin{tabular}{|c|c|c|}
\hline \multirow{2}{*}{ Standartlar/Koşullar } & \multicolumn{2}{|c|}{ Evet/Var/Uygun } \\
\hline & $\mathbf{n}$ & $\%$ \\
\hline Okul bahçesinde oyun alanı var mı? & 86 & 94,5 \\
\hline Öğrenci başına düşen oyun alanı yeterli mi? & 44 & 48,3 \\
\hline Bahçede bulunan ağaçlar uygun mu? & 87 & 95,6 \\
\hline Su kaynağı şebeke suyu mu? & 91 & 100,0 \\
\hline Su deposu var mi? & 40 & 44,0 \\
\hline Bodrum katında derslik var mı? & 6 & 6,6 \\
\hline Koridorun her iki yanında derslik var mı? & 88 & 96,7 \\
\hline Kapalı beden eğitimi salonu var mı? & 22 & 24,2 \\
\hline Öğrenci başına düşen beden eğitimi salonu alanı uygun mu? & 5 & 5,5 \\
\hline Dersliklerde ortalama öğrenci sayısı uygun mu? & 77 & 85,2 \\
\hline Öğrenci başına düşen derslik alanı uygun mu? & 2 & 2,2 \\
\hline Erkek öğrenci kabin sayısı uygun mu? & 58 & 63,6 \\
\hline Erkek öğrenci lavabo sayısı uygun mu? & 78 & 85,4 \\
\hline Kız öğrenci kabin sayısı uygun mu? & 65 & 71,6 \\
\hline K1z öğrenci lavabo sayısı uygun mu? & 87 & 95,5 \\
\hline Engelli rampası var mı? & 60 & 65,9 \\
\hline Engelli asansörü var mı? & 19 & 20,9 \\
\hline Engelli wc var mı? & 46 & 50,5 \\
\hline Kantin var mı? & 75 & 82,4 \\
\hline Ecza dolabının yerden yüksekliği uygun mu? & 76 & 83,5 \\
\hline
\end{tabular}

Araştırmaya alınan okulların 100 metreden az mesafede \%80,2'sinin market/seyyar satıc1, \%31,9'unun ise tren yolu/ana cadde/ana yol bulunmaktaydı. Okulların \%97,8'inin sinırlarında duvar veya çit vardı (Tablo 2). Araştırmaya katılan okulların \%25,3' ünün lavabosunda el kurutma cihazı veya kağıt havlu, \%30,8'inin tuvaletlerinde tuvalet kağıdı vard1. Okullarda tuvalet temizliği yeterli olan okul oranı $\% 48,4$ olarak belirlendi (Tablo 3).

\section{Tartıșma}

Manisa il merkezindeki devlet ilkokul ve ortaokullarının fiziki ve çevresel koşullarının değerlendirilmesi amacıyla yapılan bu araştırmada elde edilen bulgular, TSE'nin “TS 9518 (2000) İlköğretim Okullar1-Fiziki Yerleşim-Genel Kurallar", "TS 12014 (1996) Çevre Sağlığı-Okullar" ve "TS 9111 (2011) Özürlüler ve Hareket Kisıtlılığ1 Bulunan Kişiler İçin Binalarda Ulaşılabilirlik Gerekleri"' standartlarına göre değerlendirildi ve tartışıldı. "TS 9518 (2000) Şehir İlkokulları-Genel Kurallar" standardına göre; okulun inşa edildiği alan, bar, kahvehane, hapishane gibi yerlerden en az 100 metre uzaklıkta olmalı ve hava kirliliğinin olmadığı veya en az olduğu yerde seçilmelidir. Araştırmaya alınan okulların önemli bir kısmının 
Tablo 2. Okulların Güvenlik Koşullarının Dağılımı (n=91)

\begin{tabular}{lll}
\hline \multirow{2}{*}{ Standartlar/Koşullar } & Evet/Var \\
\cline { 2 - 3 } & n & \% \\
\hline Okula 100 metreden az mesafede tekel bayi var mı? & 14 & 15,4 \\
\hline Okula 100 metreden az mesafede bar vb. alkollü içecek satan yer var mı? & 7 & 7,7 \\
\hline Okula 100 metreden az mesafede internet oyun salonu var mı? & 19 & 20,9 \\
\hline Okula 100 metreden az mesafede sanayi tesisi var mı? & 11 & 12,1 \\
\hline Okula 100 metreden az mesafede market, seyyar satıcı var mı? & 73 & 80,2 \\
\hline Okula 100 metreden az mesafede tren yolu, otoyol/anayol/ana cadde var mı? & 31,9 \\
\hline Okul çıışında yaya geçidi veya trafik 1şık var mı? & 29 & 30,8 \\
\hline Okul çıkşında trafik polisi veya görevli var mı? & 28 & 4,4 \\
\hline Okul sınırlarında duvar veya çit var mı? & 4 & 97,8 \\
\hline Okulda yangın söndürme araçları var mı? & 89 \\
\hline Yangın söndürme araçlarının düzenli kontrolü yapılıyor mu? & 87 & 95,6 \\
\hline Okulda yangın merdiveni var mı? & 86 & 94,5 \\
\hline Yangın merdiveni kilitli mi? & 45 & 49,5 \\
\hline Okul binası depreme dayanıklı mı? & 23 & 45,1 \\
\hline Merdivenlerde korkuluk var mı? & 47 & 51,6 \\
\hline Koridor zemininde kaymayı engelleyecek malzeme var mı? & 84 & 92,3 \\
\hline
\end{tabular}

Tablo 3. Okulların Hijyen Koşularının Dağılımı (n=91)

\begin{tabular}{llc}
\hline \multirow{2}{*}{ Standartlar/Koşullar } & \multicolumn{2}{c}{ Evet/Var/Uygun } \\
\cline { 2 - 3 } & n & \% \\
\hline Dersliklerin temizlik durumu uygun mu? & 87 & 95,6 \\
\hline Dersliklerde bulunan çöp kovası var mı? & 89 & 97,8 \\
\hline Lavaboda temizlik maddesi var mı? & 66 & 72,5 \\
\hline Lavaboda el kurutma cihazı veya kağıt havlu var mı? & 23 & 25,3 \\
\hline Lavabonun tuvaletten ayrı mı? & 80 & 87,9 \\
\hline Tuvalette çöp kovası uygun mu? & 67 & 73,6 \\
\hline Tuvaletlerde tuvalet kağıdı var mı? & 28 & 30,8 \\
\hline Tuvaletin temizlik durumu uygun mu? & 44 & 48,4 \\
\hline Kantinde çöp kovası var mı? & 73 & 80,2 \\
\hline Kantin personeli önlük, eldiven kullanıyor mu? & 26 & 32,9 \\
\hline
\end{tabular}

100 metre yakınında, tren yolu/ana cadde/ana yol bulunmaktadır. Okulların anayol/ana cadde üzerinde olması, öğrencilerin ve okul çalışanlarının trafik kazası riskini arttırmasının yanında taşıtlardan çıkan egzoz gazına ve gürültüye maruz kalmasına neden olmaktadır. Okul kapılarının ana caddeye açılma durumlarının fazla olmasına rağmen çocukların hızlı çıkışını önleyici önlemlerin yeterli olmaması tehlikeyi büyütmekte ve güvenlik sorunlarına yol açmaktadır [5]. Kahraman ve ark.'nın (2019) nitel çalışmasında okul güvenliği ile ilgili 362 haber incelenmiş ve okul güvenlik sorunlarına yönelik temalar belirlenmiştir. Çalışmada okulların fiziksel güvenliğine ilişkin; bina, ulaşım, hijyen etkenleri ve altyapı ile ilgili güvenlik olayları olmak üzere dört farklı kategoriye ulaşılmıştır [15].

İncelenen okulların sadece yaklaşık yarısının yeterli büyüklükte bahçeye sahip olduğu saptanmıştır. Artan ögrenci sayısı ve derslik ihtiyacını karşılamak için okul bahçesine ek bina yapılması okul oyun alanını azaltmış olabilir. Çocukların fiziksel, zihinsel ve psikososyal gelişiminde oyun ve oyun alanları çok önemlidir. Örs'ün (2014) Antalya'da ilkokul öğrencilerinin velileriyle yürüttüğü çalışmada velilerin çoğu okul bahçe alanının yetersiz olduğu bildirmiştir [16].

"TS 9518 (2000) Şehir İlkokulları-Genel Kurallar" standardına göre; her 20 kız ve her 25 erkek öğrenci için bir kabin ve her $4 \mathrm{k} 1 \mathrm{z}$ ve her 2 erkek kabini içinde de bir lâvabo bulunmalıdır. Okul tuvaletlerinin sayıca yetersiz olmasının yanı sıra çoğunluğunun temizliğinin yetersiz olduğu bulundu. Çalışma bulguları benzer çalışma sonuçlarıyla benzerdir [16]. Tuvaletlerin sayıca yetersiz, hijyenin kötü olması ögrencilerde konstipasyon, enürezis ve fekal-oral yolla geçen bulaşıcı hastalıkların sıklığını arttırabileceği için sağlığı olumsuz etkiler. Ayrıca wc kullanmak istemeyen öğrencilerde idrar yolu sorunlarına yatkınlık da olabilmektedir.

Bina girişlerinde, TS 9111 ve TS 12576 no.lu standartlarda ve engellilerle ilgili 17.12.2009 tarihli ve 9648 (2009/90) sayılı Genelge' de açıklandığı şekilde gerekli tedbirler alınmalıdır. Zemin katta fiziksel engelliler için bir adet wc düzenlenmeli, kolay ulaşılabilir bir yerde fiziksel engelli asansörü ve engelli rampası yapılmalıdır. Okulların $\% 50,5$ 'inde engelli wc, \%20,9'unda engelli asansörü ve $\% 65,9$ 'unda rampa bulunmaktadır. Bu durum ilgili 
genelgeyle belirtilen düzenlemelerin tüm okullarda yaygınlaşmadığını düşündürmüştür.

TS 9518 ve TS 12014 sayılı standartlara göre sinıflarda ortalama öğrenci sayısı 35 'in altında ve öğrenci başına düşecek olan derslik alanı en az 1,2 $\mathrm{m}^{2}$ olmalıdır. Okulların çoğunda öğrenci sayısı uygun iken okulların sadece \%2,2'sinde öğrenci başına düşen derslik alanı yeterlidir. Sınıfta öğrenci sayısı arttıkça özellikle hava yoluyla bulaşan hastalıkların yayılma riski artacaktır. Öğrencilerin derse adapte olması olumsuz yönde etkilenecek, öğretmenlerin her öğrenciye ayıracağ zaman azalacak dolayısıyla eğitim kalitesi düşecektir.

Okullarda obezite ile mücadelede yeterli ve dengeli beslenme ve düzenli fiziksel aktivite alışkanlığının kazandırılması için "Beslenme Dostu Okul Projesi" ile okullarda sağlıklı beslenme ve hareketli yaşam konularında duyarlılığın arttırılması ve bu konuda yapılan iyi uygulamaların desteklenmesi ile okul sağlığının daha iyi düzeylere çıarılması hedeflenmektedir. Çalışma kapsamındaki okulların sadece \%4,4' ü Beslenme Dostu Okul sertifikasına sahiptir. Araştırmaya katılan okulların çoğunluğunda kantin vardır, düzenli portör muayeneleri yapılmaktadır. Obeziteyi arttırıcı ve sağlıksız kabul edilen kola, cips yiyecekler okulların çoğunda satılmaktadır. Frerichs ve ark.'nın (2015) çalışmasında okulun fiziksel ortamının sağlıklı beslenmenin sağlanmasında önemli bir rolü olduğu bildirilmiştir [17]. Okul kantin çalışanlarının kişisel hijyen ve gida hijyeni konusunda bilgi düzeylerinin incelendiği çalışmada kantin çalışanlarının kişisel hijyen ve gida hijyeni konusunda bilgi düzeylerinin iyi olduğu saptanmıştır [18].

Araştırmaya alınan okulların çoğunlukla birinci basamak sağlık kuruluşlarına yakın olduğu bulunmuştur. "TS 12014, Çevre Sağlığı-Okullar" standardına göre okullarda bir revir bulunmalı ve özellikle okul ve çevre sağlığı konusunda eğitim almış okul hemşiresi istihdam edilmelidir. Araştırma kapsamındaki okulların çok az bir kısmında revir ve sağlık personeli bulunmaktadır. Okul sağlık ekibi ve okul sağlığı hemşiresini olması sağlıklı ve güvenli bir okul çevresinin sağlanması ve sürdürülmesine katkı sağlayacaktır [19].

Okulların temizlik ve hijyen konusunda teşvik edilmesi amacıyla temizlik açısından 100 üzerinden 90 alan okullarına beyaz bayrak verilmektedir. Araştırmadaki okulların \%31,9'u bu sertifikaya sahiptir.

\section{Sonuç}

Okul çocuklarının ve okul çalışanlarının optimal sağlık düzeyini kazanmaları ve sürdürmelerini sağlamak için okul çevre sağlığ hizmetleri çok önemlidir. Manisa il merkezindeki 91 ilköğretim okulundan elde edilen sonuçlar doğrultusunda bazı önerilerde bulunulabilir.

Cadde/anayol ve tren yolu yakınında bulunan okulların giriş çıkış saatlerinde geçiş güvenliğini sağlayacak bir görevli bulundurulmalıdır. Beslenme dostu okul, beyaz bayrak projesi gibi projelerin Sağlık Bakanlığı ve Milli Eğitim Bakanlığı tarafından teşviki arttırılmalıdır. Okul sağlığı hizmetlerinin temel taşını sağlık personeli oluşturur. Sağlık sorunlarını saptamasının yanı sıra okul çevre sağlığını denetler ve aksaklıkları ilgililere ileterek gereğini yapılmasını sağlar, bulaşıcı hastalıkları ortaya çıkmasını ve yayılmasını önler. Okullarda sağlık personelinin bulundurulmasına yönelik başta hemşireler olmak üzere tüm toplumun bilinçlenmesi sağlanmalıdır. Bulaşıcı hastalıklardan korunmak için hijyen eğitimi verilmeli, lavabolarda yeterli ve gerekli temizlik malzemesi bulundurulmalıdır. Kantinlerde uygun gida satışına izin verilmeli ve düzenli aralıklarla denetlenmeli, öneriler okul idaresine ve daha üst makamlara iletilmelidir.

\section{Teşekkürler}

Araştırma verilerinin toplanmasını destekleyen kurum yetkililerine teșekkür ederiz.

\section{Referanslar}

1. Pekcan, H, Okul Sağlığı. Güler, Ç, Akın, L, (eds.): Halk Sağlığı Temel Bilgiler, Hacettepe Yayınlart, Ankara, 2015, 440-83.

2. T.C. Milli Eğitim Bakanlığı, Okul Sağlığı Çevre Sağlığı Modülü, https://okulsagligi.meb.gov.tr/www/okul-sagligi-

hizmetleri/icerik/29, 2011 (Erişim Tarihi: 17.06.2019),

3. Öncel, S, Sağlığı Geliştiren Okullar Kavramı ve Bu Kapsamda Belirlenen Uluslararası Standartlar, Turkiye Klinikleri Journal of Public Health Nursing-Special Topics, 2016, 2(1), 96-101.

4. Woolner, P, Hall, E, Higgins, S, McCaughey, C, \& Wall, K, A sound foundation? What we know about the impact of environments on learning and the implications for Building Schools for the Future, Oxford Review of Education, 2007, 33(1), 47-70.

5. Temel, A.B, Sağlıklı ve Güvenli Okul Çevresi. İçinde: Gözüm, S, (eds): Okul Dönemindeki Çocukların Sağlığının Geliştirilmesi, Vize Yayıncilık, Ankara, 2016, s.270-316.

6. Çobanoğlu, F, Badavan, Y, Başarılı okulların anahtarı: etkili okul değişkenleri, Pamukkale Üniversitesi Sosyal Bilimler Enstitüsü Dergisi, 2017, (26), 114-134.

7. T.C. Sağlık Bakanlığı, Hemşirelik Yönetmeliğinde Değişiklik Yapılmasına Dair Yönetmelik, https://www.saglik.gov.tr/TR,10526/hemsirelik-yonetmeligindedegisiklik-yapilmasina-dair-yonetmelik-yayimlanmistir.html, 2011 (Erişim Tarihi: 18.06.2019).

8. Sürdürülebilir Kalkınma Amaçları, http://www.un.org.tr/belgeler/surdurulebilir-kalkinma-hedefleri/ 2019 (Erişim Tarihi:18.06.2019).

9. World Health Organization Don't pollute my future! The impact of the environment on children's health, https://www.who.int/ceh/publications/don-t-pollute-my-future/en/, 2017 (Erişim Tarihi: 18.06.2019).

10. Temel, F, Levent, A, Vaizoğlu, S.A, Özgür, K, Asil, K, Halas, A.M, Güler, Ç, Altındağ İlçesindeki Bir İlköğretim Okulunun Çevre sağlığg yönünden değerlendirilmesi, Uludağ Üniversitesi Tip Fakültesi Dergisi, 2006, 32(1), 1-8.

11. Paulson, J, Barnett, C, WHO's in charge of children's environmental health at school? New solutions: a journal of environmental and occupational health policy, 2010, 20(1), 3-23.

12. Türk Standardı 9518: İlköğretim Okulları, Fiziki Yerleşim, Genel Kurallar, 2000, Türk Standartları Enstitüsü, Ankara.

13. Türk Standardı 12014: Çevre Sağlığı-Okullar, 1996, Türk Standartları Enstitüsü, Ankara.

14. Türk Standardı TS 9111: Özürlüler ve Hareket Kısıtlılığı Bulunan Kişiler İçin Binalarda Ulaşılabilirlik Gerekleri, 2011, Türk Standartları Enstitüsü, Ankara.

15. Kahraman, H, Şemin, F.K, Uğurlu, C.T, Okul Güvenliği: Türkiye'de Basina Yansiyanlar/School Security: Reflected to the Press in Turkey, Journal of History Culture and Art Research, 2019, 8(1), 392-408.

16. Örs, M, Çevre Sağlığı Bakımından İlköğretim Okullarının Durumu ve Velilerin Bu Konudaki Öğrenme Gereksinmeleri (Manavgat İlçesi Örneği), Pegem Eğitim ve Öğretim Dergisi, 2014, 4(4), 77-102.

17. Frerichs, L, Brittin, J, Sorensen, D, Trowbridge, MJ, Yaroch, AL, Siahpush, M, Huang, TTK, Influence of school architecture and design on healthy eating: a review of the evidence, American journal of public health, 2015, 105(4), e46-e57. 
18. Meydanlığlu, A, Akcan, A, Bir Kent Ölçeğinde Okul Kantin Çalışanlarının Kişisel Hijyen ve Gıda Hijyeni Konusunda Bilgi Düzeyleri, Turkiye Klinikleri Journal of Public Health NursingSpecial Topics, 2016, 2(1), 68-73.

19. Bektaş, M, Aydın, B, Okul Hemşiresinin Rol ve İşlevleri, Turkiye Klinikleri Journal of Pediatric Nursing-Special Topics, 2018, 4(1), 52-64.

http://edergi.cbu.edu.tr/ojs/index.php/cbusbed isimli yazarın CBU-SBED başlıklı eseri bu Creative Commons Alıntı-Gayriticari4.0 Uluslararası Lisansı ile lisanslanmıştır.

cc) (7) \& 